EFFECTS OF EMPOWERING LEADERSHIP 1

\title{
Can Empowering Leaders Affect Subordinates' Well-Being and Careers Because They Encourage Subordinates’ Job Crafting Behaviors?
}

\author{
Minseo Kim and Terry A. Beehr \\ Department of Psychology \\ 233 Sloan Hall \\ Central Michigan University \\ Mount Pleasant, Michigan 48859, U.S.A.
}

Some of these data were presented at the $12^{\text {th }}$ International Conference on Occupational Stress and Health, "Work, Stress, and Health 2017: Contemporary Challenges and Opportunities," Minneapolis, MN.

\section{Author biographies}

Minseo Kim is an I/O Psychology PhD student at Central Michigan University. Her research inte rests include occupational stress, leadership, motivation, careers, and employee well-being.

Terry A. Beehr is a Professor of Psychology and member of the I/O Psychology faculty at Centr al Michigan University. His research interests include occupational stress, retirement, leadership, motivation, and careers.

\section{Corresponding Author:}

Minseo Kim, Department of Psychology, College of Humanities and Social and Behavioral Sciences, Central Michigan University, Mount Pleasant, MI 48859, U.S.A.

Email: minseokim0331@gmail.com 
EFFECTS OF EMPOWERING LEADERSHIP 2

\begin{abstract}
This study examined the effects of empowering leadership on employees' well-being and career outcomes through their job crafting behaviors over three time points during a two-month period. With 325 full-time employees, results from structural equation modeling demonstrated that empowering leadership was positively associated with employees' job crafting behaviors even after controlling for proactive personality. Job crafting resulted in lower levels of physical and depressive symptoms and higher levels of career satisfaction and commitment. Together, these findings highlight the role of empowering leadership in encouraging and facilitating job crafting behaviors of employees, which in turn leads to subjective career success as well as physical and psychological well-being.
\end{abstract}

Keywords: empowering leadership; job crafting; employee well-being; career satisfaction; career commitment 
EFFECTS OF EMPOWERING LEADERSHIP 3

\section{Can Empowering Leaders Affect Subordinates' Well-Being and Careers Because They Encourage Subordinates' Job Crafting Behaviors?}

Organizations frequently strive to design and redesign jobs to adapt to changing and unpredictable environments, but relying on top-down job design by organizations may be getting harder as the work environment becomes more dynamic. Instead, employees often take responsibility for their own work design. Wrzesniewski and Dutton (2001) argued that employees can shape the boundaries of their jobs and create a work environment that fits their skills, preferences, and competences, and this process of influencing one's job is called job crafting. Thus, job crafting is a kind of self-oriented behavior that individuals use to improve their fit with their jobs, revise the meaning of their work, and change their work identity. Job crafting is a self-initiated form of work behavior in which individuals actively change the perceived characteristics of their jobs regarding task, relationship, and cognitive appraisal in order to better align them with their goals and needs (Wrzesniewski \& Dutton, 2001). Previous research has shown that person characteristics, especially employees' proactive personalities, can predict job crafting, but the present study argues that favorable environmental characteristics, namely empowering leaders, can also result in more job crafting. The present study examined the ability of leaders to promote job crafting by their behaviors involved in empowering leadership. In addition, we examined two categories of outcomes of job crafting, employee well-being and subjective career success (Figure 1).

An individual's job crafting behavior can be affected by others in the work group or by network contacts who frequently communicate about task-related issues (Bizzi, 2016), and a supervisor or leader is one of the more important people who communicates about tasks. Empowering leadership refers to a set of behaviors of the leaders who share their power and 
authority, foster self-leadership, and assign more responsibilities to their subordinates through providing greater autonomy from bureaucratic constraints, enhancing the meaning of work, encouraging participation in decision making, and expressing confidence in high performance (Ahearne, Mathieu, \& Rapp, 2005; Arnold, Arad, Rhoades, \& Drasgow, 2000; Zhang \& Bartol, 2010), as well as offering developmental support through coaching and modeling (Amundsen \& Martinsen, 2014). A leader is an important person in the social context and plays a role in enhancing or reducing an employee's motivation to behave proactively (Parker \& Wu, 2014). Thus, it is important to study leaders because they provide their subordinates with more or less delegation, resources, or different motivations (reasons) to engage in job crafting behaviors, depending on their leadership styles; yet few studies have examined the effect of leader behaviors on employees' job crafting. To address this limitation, we propose a link between empowering leadership and employee self-initiated behaviors (seeking social and structural resources and seeking challenges; i.e., job crafting). Leaders should encourage employees to craft their own jobs, because job crafting can result in more motivation to accomplish the jobs, more work engagement (Petrou, Demerouti, Peeters, Schaufeli, \& Hetland, 2012), better performance (Bakker, Tims, \& Derks, 2012), and experiencing more positive emotions and psychological functioning (Slemp \& Vella-Brodrick, 2014).

The present study is one of the first to examine employee general well-being as a jobcrafting benefit, and it asks the question, can leaders affect subordinates' well-being because they encourage subordinates' job crafting? Although job crafting has received increasing attention in organizational research, and prior studies suggested that job crafting may have some positive effects for individuals and organizations, research on the well-being effects of job crafting other than job burnout and engagement is rare (Bakker, Rodríguez-Muñoz, \& Vergel, 2016; Harju, 
Hakanen, \& Schaufeli, 2016; Petrou, Demerouti, \& Schaufeli, 2015). General well-being refers to people's overall state of being happy and healthy in life (Moen, 1996), and the present study examines the effect of job crafting (e.g., increasing social and structural job resources and seeking challenges; Tims, Bakker, \& Derks, 2012) on general well-being in terms of employees' physical health problems and depression.

The second potential benefit of job crafting may be career success. The present study focuses on subjective career success consisting of two components: career satisfaction (positive feelings or attitudes about the progress of one's career; Greenhaus, Parasuraman, \& Wormley, 1990) and career commitment (one's motivation to continue working in a chosen career role; Hall, 1971). According to arguments by Wrzesniewski and Dutton (2001), employees can sometimes modify the nature of their jobs to better fit their view of what their careers should be, with the likely result being better satisfaction with their careers. Job crafting consists of behaviors that should result in increased fit; thus employees who are dissatisfied with parts of their job can alter those job dimensions to achieve better alignment with their work motivation and career goals, increasing person-job fit and consequently meaningfulness in their work and careers (Tims, Derks, \& Bakker, 2016). Job crafting employees are more likely to develop a deeper understanding of their work and career paths, which may lead to subjective career success in the forms of career satisfaction and career commitment.

The present study makes several contributions to the literature. First, we add empowering leadership as an antecedent of job crafting to the well-established individual differences (e.g., proactive personality, Bakker et al., 2012; self-efficacy, Tims, Bakker, \& Derks, 2014) and to the more limited evidence about some job characteristics (e.g., job autonomy, Niessen, Weseler, \& Kostova, 2016). 
It is important to know that leaders or supervisors can be a point of influence on employees' crafting actions. Knowing this will enable us to gain a better theoretical understanding of job crafting. Moreover, for applied purposes, it might influence organizations to encourage their supervisors to promote job crafting. Second, the present study broadens the known outcomes of job crafting by expanding well-being related outcomes from a previous focus on job related well-being such as work engagement and job burnout (emotional exhaustion) to the more general well-being in life (physical complaints and depression). This will let us know if job crafting is important to employee well-being outside the job. Third, we contribute to both leadership and careers literature by identifying the relationship between empowering leadership and subjective career success via job crafting. The indirect relationships of empowering leadership with subordinates' general well-being and careers via job crafting have not been examined previously. Uncovering beneficial effects of empowering leadership and job crafting may be helpful for both employees and organizations in terms of creating a productive and healthy workplace.

The concept of job crafting

As noted earlier, employees can engage in job crafting regarding their tasks, their relationships, and their cognitions about the job (Wrzesniewski \& Dutton, 2001). By engaging in task crafting, employees can alter the type, number, or scope of the tasks they accomplish, which enables them to minimize negative aspects of job or maximize interesting job content. Through relational crafting, employees can change the quality or number of relationships they have with others at work; they make choices about whom they interact with or avoiding superiors and coworkers they dislike. Lastly, employees may engage in cognitive crafting and change the way 
they think about their jobs, thereby altering their perceptions of the underlying meaning of their job (Wrzesniewski \& Dutton, 2001).

Based on the job demands-resources model (JD-R; Bakker \& Demerouti, 2007), job crafting can be described as proactive activities that can increase (1) social resources (e.g., asking for supervisory coaching and feedback) and (2) structural resources (e.g., task variety, developing capabilities, and learning new things), but also can increase (3) challenging demands (e.g., asking more responsibility and taking on extra tasks) or (4) decrease hindering demands (e.g., avoiding difficult decisions or unpleasant customers) (Tims et al., 2012). Job crafting is an individualized proactive approach to job re-design compared with the 'one-size-fits-all' approaches that are often initiated by the organization (Demerouti \& Bakker, 2014; Grant \& Parker, 2009). Both resources and challenging demands can have good outcomes for employees (e.g., Lepine, Podsakoff, \& Lepine, 2005; Webster, Beehr, \& Love, 2011), especially if the demands are accompanied by resources based on the JD-R model (e.g., Demerouti \& Bakker, 2014; Nielsen \& Abildgaard, 2012; Wang, Demerouti, \& Bakker, 2017).

The antecedent of job crafting: empowering leadership

Job crafting research has focused on its positive effects, but its antecedents are not wellunderstood, other than personality (Bipp \& Demerouti, 2015; Plomp, Tims, Akkermans, Khapova, Jansen, \& Bakker, 2016) and a few specific job characteristics (Niessen et al., 2016). The present study, however, proposes empowering leadership as a potential predictor of job crafting. Some studies suggest that a leader could play a role in determining the possibilities for subordinates' job crafting behaviors and increasing their job resources (Schaufeli, 2015; Wrzesniewski \& Dutton, 2001). Empowering leaders provide the subordinates with the latitude or autonomy to design their own work, and the autonomy provided by empowering leaders can 
trigger subordinates' job crafting behaviors. We expect that empowering leader behaviors, which foster autonomy, meaningfulness of work, participation in decisions, and expressing confidence in performance, will encourage employees' job crafting behaviors, thereby increasing their job resources.

Specifically, empowering leadership encompasses behaviors such as delegating, encouraging initiative, fostering self-leadership skills, granting autonomy and authority, expressing confidence in high performance, and offering developmental support through coaching, modeling, and feedback (Ahearne et al., 2005; Amundsen \& Martinsen, 2014; Arnold et al., 2000). Because of its emphasis on autonomy, power sharing, and motivation support in employees, empowering leadership has been proposed to be a strong driver of fostering the psychological feeling of empowerment (Kim \& Beehr, 2017; Zhang \& Bartol, 2010) and selfefficacy (Kim \& Beehr, in press), as well as to be distinct from other positive leadership styles (Pearce, Sims, Cox, Ball, Schnell, Smith, \& Trevino, 2003; Tekleab, Sims, Yun, Tesluk, \& Cox, 2008).

The autonomy resulting from empowering leadership should facilitate employees' job crafting. Prior studies have shown that increased autonomy is positively related to proactive behavior and personal initiative (Frese, Kring, Soose, \& Zempel, 1996; Hornung \& Rousseau, 2007), which contributes to employees' customization of work (Wrzesniewski \& Dutton, 2001; Leana, Appelbaum, \& Shevchuk, 2009); empowering leadership was suggested as an effective leadership style for improving subordinates' proactivity in a study by Martin, Liao, and Campbell (2013). Proactive personalities (a type of employee individual difference) have been shown to be related to job crafting (e.g., Bakker et al., 2012; Plomp et al., 2016), and we propose 
that proactivity that is encouraged by leaders (a factor in employees' environments) should also result in job crafting.

Employees whose leaders provide more freedom or choice regarding how to carry out the work because of increased autonomy are more likely to be given opportunities to rethink their work. Lyons (2008) pointed out that the decision to reshape the job is influenced by the perceived opportunity to do so. High autonomy and flexibility allow employees to adapt work roles or elements to their skills and needs, as well as change the social environment to align with their own preferences. Furthermore, discretion in work provides employees with psychologically positive opportunities to try new things while doing their jobs, because it gives them a sense of freedom and self-determination in what they do and how they do their work, a condition that represents both job resources and challenge demands in the JD-R model.

Empowering leader behaviors that are supportive and developmental, including giving constructive feedback and freedom for independent thinking (Amundsen \& Martinsen, 2014), may create a climate favorable to active learning, thereby stimulating personal initiative and job adaptation. Encouragement of participation in work process and information sharing also provide employees with opportunities to expand their knowledge on tasks and/or acquire new skills (Zhang \& Bartol, 2010). These eventually contribute to increasing employees' social and structural resources as they take on new challenges. Taken together, characteristics of empowering leadership that focuses on autonomy, power sharing, motivational support, and personal development should be closely related to individual job crafting. Therefore, job crafting is more likely to occur in resourceful work environments created by empowering leadership behaviors.

H1. Empowering leadership is positively related to job crafting. 
The consequences of job crafting: well-being and careers

Although the association between job crafting and occupational well-being (e.g., job satisfaction, work engagement, and job burnout) has been established (Tims, Bakker, \& Derks, 2013), little is known about the potential for job crafting to affect people's more general wellbeing, that is, their overall state of being happy and healthy in life (e.g., Moen, 1996), in the present study consisting of physical health and (low levels of) depression. Burnout and depression may be related to each other because both include fatigue or loss of energy, but burnout does not involve the sadness, worthlessness, and hopelessness that are features of depressive symptoms (e.g., Suls \& Bunde, 2005). Depression can be more debilitating and reflects general individual beliefs and mood, being more global in nature than burnout from the job. In addition to the psychological well-being embodied in depressed moods, the present study also examines physical symptoms as a feature of well-being. Physical symptoms have been studied as a form of physical strain due to job stressors (e.g., Spector \& Jex, 1998; Ford, Matthews, Wooldridge, Mishra, Kakar, \& Strahan, 2014), and if job crafting results in challenge demands that are accompanied by increased resources, both psychological (depression) and physical (physical complaints) strains should be reduced (e.g., Bakker, 2015; Bakker \& Demerouti, 2007; Tims et al., 2013).

Depression in particular is one of the most common mental disorders, with 16.1 million US adults suffering from depression (National Institute of Mental Health, 2015). Depression typically involves social relationship problems and lost work productivity; such mood disorders result in more than $\$ 50$ billion per year in US productivity losses as well as more sick days (APA, 2010). Because mental and physical health issues include personal and financial burden for both employees and organizations, it is important to identify potential factors that help 
prevent employee health problems; the model in Figure 1 suggests that job crafting may be one of those factors. Job crafting enables employees to seek and expand their pool of job resources, and according to the JD-R model (Bakker \& Demerouti, 2007) access to sufficient job resources protects employees against strains (Schaufeli, Bakker, \& Van Rhenen, 2009). In addition to the JD-R model, a second resources theory, the conservation of resources theory (COR; Hobfoll, $1989,2002)$ suggests that maximizing task and social job resources has a positive effect on physical and emotional well-being, because a larger pool of resources improves employees' responses to stressors and/or helps them deal with the demands of the environment. Heaphy and Dutton (2008) also found that positive social interactions at work had beneficial effects on physiological functioning (e.g., cardiovascular and immune system). Therefore, by altering their social and structure job resources, job crafter employees can optimize their physical and psychological well-being. Once employees have gained more job resources, they can attempt to increase and mobilize their resources to stay healthy (based on COR; Hobfoll, 2002). Recent research on job crafting supported this argument, showing that job crafting behavior increasing resources predicted the presence of even more job resources a month later (termed a resource spiral) (Tims et al., 2013). Increased resources lead to less strain or better well-being according to both JD-R and COR theories.

Lastly, person-job fit theory (Kristof-Brown, Zimmerman, \& Johnson, 2005) argues that poor employee well-being results from a mismatch between the needs, skills, and abilities of the individual and the characteristics of the job. Job crafting provides good opportunities to increase fit between person and environment, and thereby employees are less likely to be vulnerable to strains resulting from misfit between them. Thus, JD-R, COR, and person-environment fit principles all would predict that employees efforts to maximize resources by crafting their work 
characteristics and environments make them experience less depression and physical health problems - that is, improves their well-being.

H2. Job crafting is positively related to employees' general well-being in the form of fewer (a) physical and (b) depressive symptoms.

In addition to well-being outcomes, job crafting also has the potential to influence employees' career success. Career success reflects “positive psychological or work-related outcomes or achievements one accumulates as a result of work experiences" (Seibert, Crant, \& Kraimer, 1999, p. 417). While objective career success is defined by tangible and financial indicators (e.g., salary and promotions), subjective career success indicates individuals' feelings of being satisfied with their career, such as career satisfaction and career commitment (Abele \& Spurk, 2009; Allen, Eby, Poteet, Lentz, \& Lima, 2004). Career researchers have argued that income and promotions as indicators of objective career success can be criticized, because these indicators are dependent on employment context, such as organizations, occupational sectors, and labor-market conditions (Abele, Spurk, \& Volmer, 2011). The present study, therefore, focuses on subjective career success, which is the person's own feelings about the career. We propose that self-initiated actions represented by job crafting result in higher career satisfaction and career commitment.

Career satisfaction refers to the degree to which employees believe their career paths are consistent with their needs and purposes (Jawahar, Jawahar, Liu, \& Liu, 2016; Ng, Eby, Sorensen, \& Feldman, 2005) as well as employees holding favorable attitudes about the future trajectory of their careers (Greenhaus et al., 1990). Career commitment reflects employees' motivation to work in a chosen career role (Hall, 1971), attachment to their professions, and desire to continue to practice in them (Blau, 1985). 
Job crafting behaviors allow employees to pursue the challenges and build the resources needed for work, as well as to adjust their career pursuits based on their goals, values, and skills. These behaviors improve intrinsic work motivation, help employees attain their goals successfully, and experience enhanced meaningfulness in their work and career (Tims et al., 2016). Accordingly, their career progression may be perceived as more satisfying. By crafting their jobs, employees are more likely to explore career opportunities in ways that help them express their career goals, values, and inspirations, achieving better person-environment fit in their work. That is, job crafter employees are likely to show initiative, actively seek opportunities that serve their goals and professional development, and persist in changing things in a way that advances their interests and careers, leading to greater career satisfaction. Moreover, job crafter employees are likely to adapt to changes in their careers in ways that will maintain career satisfaction.

We also posit that job crafter employees are likely to commit to their careers, because one of the aims of crafting activities is to pursue better work meaning and identity (Cenciotti, Alessandri, \& Borgogni, 2016). By altering their work characteristics and relationships based on their internal standards in order to achieve good fit, employees are motivated to set meaningful career goals as well as experience a positive work identity, which leads to career commitment. Conversely, dissatisfaction with the characteristics of work environment (e.g., routinization and supervisory relations) was found to have a negative relationship with employees' career commitment (Wickramasinghe, 2016). Furthermore, employees who are closer to their work through job crafting are more knowledgeable about their work role and career progress, and thereby they are more likely to commit to their careers. Job crafting employees change their 
career work to fit their long-term goals and values, so that they can become more committed to their careers.

H3. Job crafting is positively related to employees' subjective career success in the form of (a) career satisfaction and (b) career commitment.

\section{Job crafting as a mediator}

We examined job crafting as a mechanism underlying the relationship of empowering leadership with general well-being and subjective career success. Empowering leader behaviors such as greater autonomy and development support (Amundsen \& Martinsen, 2014) promote employees' job crafting behaviors. Employees who engage in job crafting are changing the characteristics and meaning of their jobs, which can lead to a decrease in physical and depressive symptoms, as well as an increase in satisfaction with and commitment to their careers. Incorporating this with our previous hypotheses, as illustrated in Figure 1, we propose that job crafting mediates the relationship of empowering leadership with general well-being and subjective career success.

H4. Job crafting mediates the relationship of empowering leadership with employee wellbeing in the form of (a) physical and (b) depressive symptoms.

H5. Job crafting mediates the relationship of empowering leadership with career subjective success in the form of (a) career satisfaction and (b) career commitment. In summary, the study spans four literatures: leadership, occupational health psychology (OHP), job crafting, and careers. Because of this, it contributes to our knowledge in each of these domains by showing how each is related to variables in the other domains.

\section{Methods}

\section{Participants and procedure}


Data were collected in three waves with a one-month interval between the assessments through Mechanical Turk (MTurk), a commercial service that pays respondents for participating in surveys and that provides research participants from a broad range of jobs, people, and geographic locations. Some previous studies on leadership and job crafting have successfully employed a time lag of one month between measurements (e.g., Akkermans \& Tims, 2017; Tang, Kwan, Zhang, \& Zhu, 2016). We therefore chose a one-month time lag between each set of measurements to allow enough time for the mediator (job crafting) and outcomes to vary, but short enough to minimize attrition.

Recent studies suggested that MTurk workers tend to be highly educated and carefully read survey instructions, thereby providing higher-quality data, and the samples have good diversity in terms of age, education, and work experience (Paolacci \& Chandler, 2014; Ramsey, Thompson, McKenzie, \& Rosenbaum, 2016). We invited only full-time US employees to participate in the present study. We also restricted participation to the MTurk workers who hold a 95\% approval rating from previous Mturk assignments, consistent with existing recommendations (e.g., Buhrmester, Kwang, \& Gosling, 2011; Mason \& Suri, 2012). In order to control the quality of the data further, we followed the data screening process suggested by DeSimone, Harms, and DeSimone (2015) and attention-check filter methods outlined by Peer, Vosgerau, and Acquisti (2014). That is, we included several attention-check items, we included some scales with reverse-worded items to screen out respondents who provide consistently positive or consistently negative answers regardless of the item wording, we eliminated data for respondents who selected many of the same responses $(80 \%)$ overall on the survey or whose answers were extreme outliers, and we eliminated data for respondents who completed the survey more than four times as fast as the average participant. 
Initially, 641 full-time US employees completed the first survey, but 41 responses were eliminated due to respondents' failures on attention check questions. To ensure if MTurk workers carefully read the questionnaires, we included reversed-wording questions. That is, we asked the same question once in the positive way, and once using negative words. Additionally, participants were periodically asked to choose one specific answer option (e.g., "please select 'strongly agree"') or were asked to answer general questions that typically have a correct answer (e.g., the sea is usually blue. Disagree -Agree). Of these, 523 responded to the second survey a month later; data for 87 of them were dropped due to suspected low effort responding, failed attention checks, and mismatched codes between time 1 and time 2 . We thus sent an invitation email to 436 respondents for the final survey a month after the second survey. Of these, 370 competed the final survey; 45 responses were deleted due to outliers ( $\pm 3.0 S D$ from the mean) (26 cases) and mismatched codes (19 cases) across time points. After these cases were deleted, there were no multivariate outliers. Analysis of the data both with and without the outliers revealed almost identical results. The hypotheses were tested with a final sample of 325 responses (62\% response rate from the initial sample): $56.5 \%$ were male, $81.5 \%$ white, and $68.8 \%$ had at least a bachelor's degree. The mean age of participants was 35.44 years $(S D=$ 9.59), and they worked an average of 40.75 hours per week $(S D=7.41)$ and worked in their current organization for an average of 6.58 years $(S D=5.67)$. This sample was employed in a variety of industries (e.g., health care, education, finance, retail, and information technology); and $62.2 \%$ were line employees, $15.4 \%$ supervisors, $16.6 \%$ managers, and $5.8 \%$ upper managers or executives.

\section{Measures}


The measures were taken at different times in order both to reduce the possible effects of common method variance on the relationships among the variables (Podsakoff, MacKenzie, \& Podsakoff, 2012) and to measure the variables in a sequence matching the proposed causal model in Figure 1; the predictor, empowering leadership, was measured at Time 1, the mediator, job crafting, was measured at Time 2, and the outcomes, employee well-being and subjective career success, were measured at Time 3 . We included proactive personality at Time 2 as a control variable when analyzing the prediction of job crafting by empowering leadership. All study variables were assessed using original scales to retain their favorable psychometric properties (good validity and reliability), and thus some scales were measured using a 5-point Likert scale while others were captured with a 7-point scale.

Empowering leadership (T1). For empowering leadership, we used Zhang and Bartol's (2010) 12-item measure $(\alpha=.89)$, which was originally from Ahearne et al (2005). It includes four dimensions: autonomy (e.g., "My supervisor allows me to do my job my way”), meaningfulness of work (e.g., "My supervisor helps me understand the importance of my work to the overall effectiveness of the company"), participation in decision making (e.g., "My supervisor solicits my opinion on decisions that may affect me"), and confidence in high performance (e.g., "My supervisor expresses confidence in my ability to perform at a high level") rated on a 5-point Likert scale from 1 (strongly disagree) to 5 (strongly agree).

Job crafting (T2). Job crafting was measured with 15 items $(\alpha=.91)$ developed by Tims et al. (2012). The scale captures three dimensions of job crafting behaviors: increasing structural job resources (e.g., "I try to develop myself professionally”), increasing social job resources (e.g., "I ask others for feedback on my work performance"), and increasing challenging job demands (e.g., "If there are new developments, I am one of the first to learn about them and try 
them out"). Respondents indicated the frequency of each crafting behavior on a 5-point Likert scale from 1 (never) to 5 (very often).

General well-being (T3). Two aspects of employee well-being were measured: physical complaints and depression. To measure physical complaints, respondents completed a 12- item $(\alpha=.85)$ version of the Physical Symptoms Inventory (PSI) developed by Spector and Jex (1998). An example item is "How often have you experienced a headache?" answered on a 5point Likert scale ranging from 1 (not at all) to 5 (everyday).

To measure depression, we used Dormann and Zapf's (2002) shortened three-item ( $\alpha$ $=.81$ ) version of Mohr's (1986) depressive symptoms scale. An example item is "I have sad moods" rated on a 5-point Likert scale from 1 (never) to 5 (every day).

Subjective career success (T3). Two subjective career outcomes were measured: career satisfaction and career commitment. Career satisfaction was measured with five items $(\alpha=.94)$ from Greenhaus et al. (1990). An example item is "I am satisfied with the success I have achieved in my career" rated on a 5-point Likert scale from 1 (very dissatisfied) to 5 (very satisfied).

Career commitment was measured using the five-item $(\alpha=.88)$ scale developed by Ellemers, de Gilder, and van den Heuvel (1998). An example item is "My career is one of the most important things in my life" rated on a 7- point Likert scale from 1 (strongly disagree) to 7 (strongly agree).

Control variable. The dispositional approach proposes that job crafting may be partly determined by characteristics of employees. Consistent with this perspective, previous studies showed that proactive disposition is strongly related to crafting behaviors (Bakker et al., 2012; Plomp et al., 2016); proactive employees tend to create working conditions more conducive to 
personal success at work and actively seek opportunities to increase job resources and challenges. To examine the unique effect of the environmental variable, empowering leadership, we controlled for the individual difference variable, proactive personality, when predicting employees' job crafting behaviors. Proactive personality was measured at Time 2 using six items $(\alpha=.86)$ adapted from Bateman and Crant's (1993) scale. The short six-item scale showed strong correlations with the original 17-item scale (Claes, Beheydt, \& Lemmens, 2005) and has been used in prior studies (e.g., Parker, 1998; Wang, Hu, Hurst, \& Yang, 2014). An example item is "If I see something I don't like, I fix it" rated on a 7- point Likert scale from 1 (strongly disagree) to 7 (strongly agree). Because proactive personality was measured from the same source as the other variables (the employee), using it as a control variable helped control not only for the proactive personality construct but also for common method variance (Podsakoff et al., 2012).

\section{Results}

Table 1 presents the means, standard deviations, reliabilities, and zero-order correlations. All correlations corresponding to the paths in the hypothesized model were significant. Empowering leadership was positively related to the mediator, job crafting $(r=.33, p<.01)$, and job crafting was significantly related to all four criteria: physical complaints $(r=-.12, p<.05)$, depression $(r=-.19, p<.01)$, career satisfaction $(r=.32, p<.01)$, and career commitment $(r$ $=.42, p<.01)$. We note further that potential common method variance did not seem to result in unusually strong correlations, because the median correlation in Table 1 is only .26 .

\section{Hypotheses and model testing}

We used LISREL 8.8 (Jöreskog and Sörbom, 2006) to obtain model fit and parameter statistics. To form latent variables, the four subscales of empowering leadership and the three 
subscales of job crafting were used as indicators. The 12-item measure of physical complaints was parceled into three indicators consisting of four items each. Depression had no subscales and only three items, and thus its items served as indicators. Similarly, career satisfaction and career commitment are unidimensional constructs without subscales, and for each of them, their five items served as indicators.

The confirmatory factor analysis (CFA) or measurement model indicated a good fit to the data, $\chi^{2}(278, N=325)=654.95, p<.01 ; \mathrm{RMSEA}=.06 ; \mathrm{CFI}=.97 ; \mathrm{IFI}=.97 ; \mathrm{NNFI}=.96$, providing justification for examination of the hypothesized structural model. The hypothesized model fit the data well, $\chi^{2}(293, N=325)=831.13, p<.01 ; \operatorname{RMSEA}=.07 ; \mathrm{CFI}=.95 ; \mathrm{IFI}=.95$; $\mathrm{NNFI}=.94$. Figure 2 presents the overall structural model with standardized path coefficients All paths are significant, and thus hypotheses 1, 2, and 3 were supported. Empowering leadership was positively related to job crafting $(\beta=.24, p<.01)$. Job crafting was negatively related to physical complaints $(\beta=-.14, p<.05)$ and depressive symptoms $(\beta=-.26, p<.01)$, and it was positively related to career satisfaction $(\beta=.37, p<.01)$ and career commitment $(\beta=.48, p$ $<.01)$. Similar to previous research and theory about job crafting, the association of the control variable, proactive personality, with job crafting was strong $(r=.55, p<.01)$. Even after controlling for the effect of this individual difference, however, the path from empowering leadership to job crafting remained significant, although the path coefficient decreased from $\beta$ $=.41$ to $\beta=.24$. In sum, the model was supported, and therefore the results suggested that empowering leadership had indirect effects on employees' well-being and subject career success via job crafting.

\section{Alternative models}


The fit of the overall model is consistent with the mediation hypotheses ( $\mathrm{H} 4$ and H5). However, for further evidence about mediation, two alternative overall models were tested: One model added two direct paths from the empowering leadership to the well-being variables (physical and depressive symptoms; alternative model 1), and the other model added two direct paths from empowering leadership to the career variables (career satisfaction and career commitment; alternative model 2).

Alternative model 1 tested whether empowering leadership has direct effects on employee well-being. The additional paths for alternative model 1 did not improve or change any fit indices. But a significant direct link between empowering leadership and depression $(\beta=-.19$, $p<.01)$ was found, $\Delta \chi^{2}(2, N=325)=13.83, p=.00$. The direct link from empowering leadership to physical complaints was not significant $(\beta=-.06, n s)$.

In model 2 , empowering leadership also had direct effects on career satisfaction $(\beta=.28$, $p<.01)$ and career commitment $(\beta=.16, p<.01)\left(\Delta \chi^{2}[2]=43.35, p=.00\right)$. All paths in the proposed model remained significant. Overall, comparisons of the alternative models with the proposed model suggest that in addition to the indirect effects, empowering leadership also may have direct effects on employee psychological well-being and career outcomes.

\section{Mediation and bootstrapping}

Finally, for more rigorous tests of the mediation proposed in hypotheses 4 and 5, bootstrapping analyses were calculated using the PROCESS macro, a computational tool for mediation analysis (Hayes, 2013). Table 2 presents the direct effects and bootstrapped estimates for the indirect effects with $95 \%$ confidence intervals. Following the recommendations of Preacher and Kelley (2011), $k^{2}$ is reported as a mediation effect size. The $k^{2}$ is not sensitive to sample size, because the $k^{2}$ is the ratio of the indirect effect to the maximum possible size of the 
indirect effect given the constraints of the data (Hayes, 2013). To determine the criteria for describing the magnitude of effect sizes, Cohen's guidelines defining small (.01), medium (.09), and large (.25) effect sizes were considered (Preacher \& Kelley, 2011).

Job crafting significantly mediated the relationships of empowering leadership with depression and the two career outcomes, because their confidence intervals did not include zero, supporting mediation effects. For depression and career satisfaction, the effect size was .04 and .08 respectively, which can be interpreted as small indirect effects according to Cohen's standard. The $k^{2}$ also indicated a medium indirect effect size for career commitment $\left(k^{2}=.12\right)$. Significant direct effects of empowering leadership on depression and the career outcomes were also found $(\beta=-.19, p<.05$ for depression; $\beta=.37, p<.01$ for career satisfaction; and $\beta=.28$, $p<.05$ for career commitment).

However, job crafting did not serve as a mediator between empowering leadership and physical complaints in the bootstrapping analysis. As seen in the first row of Table 2, the direct effect from empowering leadership to physical complaints $\left(c^{\prime}=-.07, p=.17\right)$ was not significant. In addition, the estimated indirect effect of empowering leadership on the physical complaints via job crafting included zero, $\mathrm{CI}(95 \%)$ : $\mathrm{LL}=-.06, \mathrm{UL}=.00$, and thus we cannot be sure whether job crafting plays a mediating role between this relationship. Overall, both the model fit statistics and the bootstrapping results suggested that empowering leadership not only influences depression, career satisfaction, and career commitment through job crafting as a mediator, but it also has direct effects on these criteria.

\section{Discussion}

The aim of the present study was to examine the mediating effect of job crafting in the relationships of empowering leadership with employee general well-being and subjective career 
success. Empowering leader behaviors, which emphasize autonomy, delegation, motivational support, and encouraging self-development (Ahearne et al., 2005; Amundsen \& Martinsen, 2014; Zhang \& Bartol, 2010), are indeed likely to help employees craft their jobs to be more resourceful and challenging. Job crafting enables employees to invest their current resources (e.g. time and energy) into building new resources (e.g. skills and better relationships or work environments). Therefore, job crafting results in work that is more fulfilling and enhances the purpose and meaning that employees get from the daily activities they come across on the job (Slemp \& Vella-Brodrick, 2014). That is, the sense of achievement and intrinsic enjoyment from the work that the employees experience contribute to better well-being in life.

The present study contributes to our knowledge about job crafting by identifying empowering leadership as an environmental antecedent, which can be added to the wellestablished individual difference antecedents of crafting (especially proactive personality); and by showing that job crafting can not only influence job-related outcomes (e.g., emotional exhaustion from or engagement with the job) but may also influence more general well-being. Furthermore, it contributes to knowledge about careers and leadership by linking empowering leadership and job crafting with subjective career success. The specific mediation of relationships of empowering leadership with subordinates' general well-being and careers via job crafting had not been examined previously.

Job crafting is more strongly related to psychological than to physical well-being. It makes sense that job crafting allows employees to shape their work experience to increase their positive work attitudes (e.g., satisfaction), which are associated with psychosocial states more than with physical states. Eventually, perhaps by satisfying one's needs and preferences at work, employees could move towards an enhanced general well-being that is characterized by both 
fewer physical and psychological symptoms, but it may take a longer time period and awaits further research.

In addition to general well-being, the study also suggests job crafting as a way for employees to enhance subjective career success in the form of career satisfaction and career commitment. As expected, job crafting activities seem to be an effective way to maximize person-job fit and thereby to aid employees in attaining career success. The more employees are allowed to seek challenges and alter work characteristics in order to align them with their purposes and motivation, the more they develop their resources and professional roles, which in turn leads to the experience of better subjective career success.

Based on the present results, empowering leadership is connected with employees' general well-being and careers via job crafting behaviors, but it is also directly connected with depression and career success. Empowering leadership, including counselling, listening, and coaching, makes subordinates more positive about their work situation. Because of positive experiences and emotions, employees are likely to exhibit enhanced active coping skills when faced with challenges in both work and personal life, which may lead to less depression. We note that the lack of control at work is generally related to psychological ill health of employees in the previous studies (Alarcon, 2011; Spector, 2002), and job crafting can be characterized as the exercise of control over one's work. The job demands and control model (Karasek, 1979) suggested that perceived job control, such as decision-making authority, opportunities to participate in work process, and opportunities to use and learn task-relevant skills and knowledge, which all could be provided by empowering leadership, can ease psychological distress, which is related to depression. Therefore, employees working with empowering leaders may have less vulnerability to depression. 
Empowering leadership also has a direct effect on subordinates' career success, underlining the important impact of leaders on their subordinates. Empowering leadership behaviors involve career-enhancing factors, such as providing subordinates with the confidence, ability, inspiration, modeling, and authority to assume control of their work lives. Thus, employees may accomplish their tasks successfully and be motivated to plan and pursue meaningful career goals, showing greater career satisfaction and commitment.

\section{Practical implications}

Work design or environment is an important factor for employees' well-being and career success. Human resource practitioners should make an effort to encourage employees to be proactive in their jobs and to engage in behaviors that increase social and structural job resources and challenging job demands (i.e., engage in crafting). In a sense, however, organizations would not demand that individuals work on redesigning their jobs, because this would be against the definition of job crafting. In order to get around this problem, organizations can create the circumstances that facilitate and stimulate the favorable forms of crafting by encouraging leaders or managers to engage in empowering leadership behaviors. For example, encouraging employees to voluntarily engage in new projects that are interesting and challenging could help promote their careers. That is, empowering leadership might be one of the strategies for fostering job crafting behaviors, as employees who benefit from greater autonomy due to empowering leaders' motivational and development support are more likely to undertake crafting activities. Along with empowering leadership, designing programs that guide employees specifically on how to engage in job crafting behaviors may be helpful.

\section{Limitations and future research}


The present study relied on self-reported data, which is related to common method bias. However, our three-wave study design and use of a control variable with the same method helped reduce common method effects (Podsakoff et al., 2012). The three-wave design also helped to address mediating relationships. Moreover, the employees worked in a variety of occupations and industries, which may increase the generalizability of the findings. The findings revealed that empowering leadership triggers subordinates' job crafting behaviors, but future research could examine what factors strengthen or weaken this relationship. Moderators might include employees' growth needs, which is a moderator of the effects of job characteristics such as autonomy in the intrinsic job design motivation model (Hackman \& Oldham, 1976). Autonomy is related to job crafting, and employees with higher growth needs or need for personal accomplishment may more actively craft their jobs.

In addition to the job crafting conceptualization that we used in the present study, there are alternative job crafting conceptualizations (e.g., Wrzesniewski \& Dutton, 2001). Future research could examine if other conceptualizations of job crafting lead to similar results as the ones we found. Team-level studies are also needed, because if employees' tasks are highly interdependent, it may limit the flexibility and autonomy that individual employees have; as a result, it may limit the actual capability of employees to modify or craft the characteristics of their jobs, which may result in less desirable occupational and subjective well-being outcomes.

There may be other explanatory variables that were not measured in the study. It is likely, for example, that job autonomy may mediate between empowering leadership and job crafting; in fact, one facet of empowering leadership is allowing autonomy for subordinates. Because Frese et al. (1996) and Lyons (2008) indicated that job autonomy is related to proactive behaviors, there may be serial mediation from empowering leadership to job autonomy, then to 
proactive behaviors, and finally to job crafting. We would propose also adding proactive personality as another predictor of proactive behavior (instead of using it as a control variable, as in the present study), and that addition forms a new model future research.

Finally, our sample was relatively small (325 respondents who could be matched to T3 outcomes) and consisted of young employees ( $M=35.44$ years). We recommend examining the degree to which empowering leadership may influence job crafting behaviors among older employees, helping them to stay healthy and experience career success, in order to further validate our results. Additionally, the respondents might have changed their jobs during the three-month study period, and thus future research is encouraged to consider such external factors.

\section{Conclusion}

The present study demonstrates the importance of empowering leadership and job crafting in predicting employee general well-being and subjective career success. COR theory suggests that having some resources can help in obtaining more resources (a resource spiral); empowering leadership can be seen as a resource by the employee, and it leads to employeeinitiated adjustments of their jobs, which allows increasing other job resources. When individuals craft their jobs by proactively creating resourceful and challenging work environments for themselves, it results in better person-job fit. Therefore, employees should be encouraged and be given the opportunity to craft their own jobs, because job crafting can become a promising way to keep employees enthusiastic about their work, increasing career satisfaction and commitment as well as boosting their well-being. Together, the present study extended our prior understanding of the effects of job crafting by including general well-being and career-related outcomes as well as identifying an important predictor, empowering leadership. 
EFFECTS OF EMPOWERING LEADERSHIP 28 


\section{References}

Abele, A. E., \& Spurk, D. (2009). The longitudinal impact of self-efficacy and career goals on objective and subjective career success. Journal of Vocational Behavior, 74, 53-62.

Abele, A. E., Spurk, D., \& Volmer, J. (2011). The construct of career success: Measurement issues and an empirical example, Journal for Labor Market Research, 43, 195-206.

Ahearne, M., Mathieu, J., \& Rapp, A. (2005). To empower or not to empower your sales force? An empirical examination of the influence of leadership empowerment behavior on customer satisfaction and performance. Journal of Applied Psychology, 90, 945-955.

Akkermans, J., \& Tims, M. (2017). Crafting your career: How career competencies relate to career success via job crafting. Applied Psychology: An International Review, 66, 168195.

Alarcon, G. M. (2011). A meta-analysis of burnout with job demands, resources, and attitudes. Journal of Vocational Behavior, 79, 549-562.

Allen, T. D., Eby, L. T., Poteet, M. L., Lentz, E., \& Lima, L. (2004). Career benefits associated with mentoring for protégés: A meta-analysis. Journal of Applied Psychology, 89, $127-$ 136.

American Psychological Association Practice Organization. (2010). Psychologically healthy workplace program fact sheet: By the numbers. Retrieved from http://www.apaexcellence.org/assets/general/2010phwp_fact_sheet.pdf

Amundsen, S., \& Martinsen, Ø. L. (2014). Empowering leadership: Construct clarification, conceptualization, and validation of a new scale. Leadership Quarterly, 25, 487-511.

Arnold, J. A., Arad, S., Rhoades, J. A., \& Drasgow, F. (2000). The empowering leadership questionnaire: The construction and validation of a new scale for measuring leader behaviors. Journal of Organizational Behavior, 21, 249-269. 
Bakker, A. B. (2015). Towards a multilevel approach of employee well-being. European Journal of Work and Organizational Psychology, 24, 839-843.

Bakker, A. B., \& Demerouti, E. (2007). The job demands-resources model: State of the art. Journal of Managerial Psychology, 22, 309-328.

Bakker, A. B., Rodríguez-Muñoz, A., \& Vergel, A. I. S. (2016). Modelling job crafting behaviours: Implications for work engagement. Human Relations, 69, 169-189.

Bakker, A. B., Tims, M., \& Derks, D. (2012). Proactive personality and job performance: The role of job crafting and work engagement. Human Relations, 65, 1359-1378.

Bateman, T. S., \& Crant, J. M. (1993). The proactive component of organizational behavior: A measure and correlates. Journal of Organizational Behavior, 14, 103-118.

Bipp, T., \& Demerouti, E. (2015). Which employees craft their jobs and how? Basic dimensions of personality and employees job crafting behaviour. Journal of Occupational and Organizational Psychology, 88, 631-655.

Bizzi, L. (2016). Network characteristics: When an individual's job crafting depends on the jobs of others. Human Relations, 1-25.

Blau, G. J. (1985). The measurement and prediction of career commitment. Journal of Occupational Psychology, 58, 277-288.

Buhrmester, M., Kwang, T., \& Gosling, S. D. (2011). Amazon's Mechanical Turk: A new source of inexpensive, yet high-quality, data? Perspectives on Psychological Science, 6, 3-5.

Cenciotti, R., Alessandri, G., \& Borgogni, L. (2016). Psychological capital and career success over time: The mediating role of job crafting. Journal of Leadership \& Organizational Studies, 1-13. 
Claes, R., Beheydt, C., \& Lemmens, B. (2005). Unidimensionality of abbreviated proactive personality scales across cultures. Applied Psychology: An International Review, 54, $476-489$.

Demerouti, E., \& Bakker, A. B. (2014). Job crafting. In M. C. W. Peeters, J. de Jonge \& T. W. Taris (Eds.), An introduction to contemporary work psychology (pp. 414-433). London: John Wiley \& Sons.

DeSimone, J. A., Harms, P. D., \& DeSimone, A. J. (2015). Best practice recommendations for data screening. Journal of Organizational Behavior, 36, 171-181.

Dormann, C., \& Zapf, D. (2002). Social stressors at work, irritation, and depressive symptoms: Accounting for unmeasured third variables in a multi-wave study. Journal of Occupational and Organizational Psychology, 75, 33-58.

Ellemers, N., de Gilder, D., \& van den Heuvel, H. (1998). Career-oriented versus team-oriented commitment and behavior at work. Journal of Applied Psychology, 83, 717-730.

Ford, M. T., Matthews, R. A., Wooldridge, J. D., Mishra, V., Kakar, U. M., \& Strahan, S. R. (2014). How do occupational stressor-strain effects vary with time? A review and metaanalysis of the relevance of time lags in longitudinal studies. Work \& Stress, 28, 9-30.

Frese, M., Kring, W., Soose, A., \& Zempel, J. (1996). Personal initiative at work: Differences between East and West Germany. Academy of Management Journal, 39, 37-63.

Grant, A. M., \& Parker, S. K. (2009). Redesigning work design theories: The rise of relational and proactive perspectives. The Academy of Management Annals, 3, 317-375.

Greenhaus, J. H., Parasuraman, S. \& Wormley, W. M. (1990). Effects of race on organizational experiences, job performance evaluations, and career outcomes. Academy of Management Journal, 33, 64-86. 
Hackman, J. R., \& Oldham, G. R. (1976). Motivation through the design of work: Test of a theory. Organizational Behavior and Human Performance, 16, 250-279.

Hall, D. T. (1971). A theoretical model of career subidentity development in organizational settings. Organizational Behavior and Human Performance, 6, 50-76.

Harju, L. K., Hakanen, J. J., \& Schaufeli, W. B. (2016). Can job crafting reduce job boredom and increase work engagement? A three-year cross-lagged panel study. Journal of Vocational Behavior, 95, 11-20.

Hayes, A. F. (2013). Introduction to mediation, moderation, and conditional process analysis: A regression-based approach. New York, NY: Guilford Press.

Heaphy, E. D., \& Dutton, J. E. (2008). Positive social interactions and the human body at work:

Linking organizations and physiology. Academy of Management Review, 33, 137-162.

Hobfoll, S. E. (1989). Conservation of resources: A new attempt at conceptualizing stress. American Psychologist, 44, 513-524.

Hobfoll, S. E. (2002). Social and psychological resources and adaptation. Review of General Psychology, 6, 307-324.

Hornung, S., \& Rousseau, D. M. (2007). Active on the job-proactive in change: How autonomy at work contributes to employee support for organizational change. The Journal of Applied Behavioral Science, 43, 401-426.

Jawahar, I. M., Jawahar, I. M., Liu, Y., \& Liu, Y. (2016). Proactive personality and citizenship performance: The mediating role of career satisfaction and the moderating role of political skill. Career Development International, 21, 378-401.

Jöreskog, K. G., \& Sörbom, D. (2006). LISREL 8.8 [computer software]. Lincolnwood, IL: Scientific Software International. 
Karasek Jr, R. A. (1979). Job demands, job decision latitude, and mental strain: Implications for job redesign. Administrative Science Quarterly, 24, 285-308.

Kim, M., \& Beehr, T. A. (2017). Directing our own careers, but getting help from empowering leaders, Career Development International, 22, 300-317.

Kim, M., \& Beehr, T. A. (in press). Self-efficacy and psychological ownership mediate the effects of empowering leadership on both good and bad employee behaviors, Journal of Leadership \& Organizational Studies, Advance online publication. doi:

\section{$10.1177 / 1548051817702078$}

Kristof-Brown, A. L., Zimmerman, R. D., \& Johnson, E. C. (2005). Consequences of individuals fit at work: A meta-analysis of person-job, person-organization, person-group, and person-supervisor fit. Personnel Psychology, 58, 281-342.

Leana, C., Appelbaum, E., \& Shevchuk, I. (2009). Work process and quality of care in early childhood education: The role of job crafting. Academy of Management Journal, 52, 1169-1192.

Lepine, J. A., Podsakoff, N. P., \& Lepine, M. A. (2005). A meta-analytic test of the challengehindrance stressor framework: An explanation for inconsistent relationships among stressors and performance. Academy of Management Journal, 48, 764-775.

Lyons, P. (2008). The crafting of jobs and individual differences. Journal of Business and Psychology, 23, 25-36.

Martin, S. L., Liao, H., \& Campbell, E. M. (2013). Directive versus empowering leadership: A field experiment comparing impacts on task proficiency and proactivity. Academy of Management Journal, 56, 1372-1395. 
Mason, W., \& Suri, S. (2012). Conducting behavioral research on Amazon's Mechanical Turk. Behavior Research Methods, 44, 1-23.

Moen, P. (1996). A life course perspective on retirement, gender, and well-being. Journal of Occupational Health Psychology, 1, 131-144

Mohr, G. (1986). Measuring psychological complaints of workers. Frankfurt am Main, Germany: Peter Lang.

National Institute of Mental Health (2015). Major depression among adults. Retrieved from https://www.nimh.nih.gov/health/statistics/prevalence/major-depression-amongadults.shtml

Ng, T.W. H., Eby, L. T., Sorensen, K. L., \& Feldman, D. C. (2005). Predictors of objective and subjective career success: A meta-analysis. Personnel Psychology, 58, 367-408.

Nielsen, K., \& Abildgaard, J. S. (2012). The development and validation of a job crafting measure for use with blue-collar workers. Work \& Stress, 26, 365-384.

Niessen, C., Weseler, D., \& Kostova, P. (2016). When and why do individuals craft their jobs? The role of individual motivation and work characteristics for job crafting. Human Relations, 69, 1287-1313.

Paolacci, G., \& Chandler, J. (2014). Inside the Turk: Understanding Mechanical Turk as a participant pool. Current Directions in Psychological Science, 23, 184-188.

Parker, S. K. (1998). Enhancing role breadth self-efficacy: The roles of job enrichment and other organizational interventions. Journal of Applied Psychology, 83, 835-852.

Parker, S. K., \& Wu, C. H. (2014). Leading for proactivity: How leaders cultivate staff who make things happen. In D. V. Day (Ed.), Oxford handbook of leadership and organizations (pp. 380-399). Oxford: Oxford University Press. 
Pearce, C. L., Sims Jr, H. P., Cox, J. F., Ball, G., Schnell, E., Smith, K. A., \& Trevino, L. (2003). Transactors, transformers and beyond: A multi-method development of a theoretical typology of leadership. Journal of Management Development, 22, 273-307.

Peer, E., Vosgerau, J., \& Acquisti, A. (2014). Reputation as a sufficient condition for data quality on Amazon Mechanical Turk. Behavior Research Methods, 46, 1023-1031.

Petrou, P., Demerouti, E., Peeters, M. C., Schaufeli, W. B., \& Hetland, J. (2012). Crafting a job on a daily basis: Contextual correlates and the link to work engagement. Journal of Organizational Behavior, 33, 1120-1141.

Petrou, P., Demerouti, E., \& Schaufeli, W. B. (2015). Job crafting in changing organizations: Antecedents and implications for exhaustion and performance. Journal of Occupational Health Psychology, 20, 470-480.

Plomp, J., Tims, M., Akkermans, J., Khapova, S. N., Jansen, P. G., \& Bakker, A. B. (2016). Career competencies and job crafting: How proactive employees influence their wellbeing. Career Development International, 21, 587-602.

Podsakoff, P. M., MacKenzie, S. P., \& Podsakoff, N. P. (2012). Sources of method bias in social science research and recommendations on how to control it. Annual Review of Psychology, 63, 539-569.

Preacher, K. J., \& Kelley, K. (2011). Effect size measures for mediation models: Quantitative strategies for communicating indirect effects. Psychological Methods, 16, 93-115.

Ramsey, S. R., Thompson, K. L., McKenzie, M., \& Rosenbaum, A. (2016). Psychological research in the internet age: The quality of web-based data. Computers in Human Behavior, 58, 354-360. 
Schaufeli, W. B. (2015). Engaging leadership in the job demands-resources model. Career Development International, 20, 446-463.

Schaufeli, W. B., Bakker, A. B., \& Van Rhenen, W. (2009). How changes in job demands and resources predict burnout, work engagement, and sickness absenteeism. Journal of Organizational Behavior, 30, 893-917.

Seibert, S. E., Crant, J. M., \& Kraimer, M. L. (1999). Proactive personality and career success. Journal of Applied Psychology, 84, 416-427.

Slemp, G. R., \& Vella-Brodrick, D. A. (2014). Optimising employee mental health: The relationship between intrinsic need satisfaction, job crafting, and employee well-being. Journal of Happiness Studies, 15, 957-977.

Spector, P. E. (2002). Employee control and occupational stress. Current Directions in Psychological Science, 11, 133-136.

Spector, P. E., \& Jex, S. M. (1998). Development of four self-report measures of job stressors and strain: Interpersonal conflict at work scale, organizational constraints scale, quantitative workload inventory, and physical symptoms inventory. Journal of Occupational Health Psychology, 3, 356-367.

Suls, J., \& Bunde, J. (2005). Anger, anxiety and depression as risk factors for cardiovascular disease: The problems and implications of overlapping affective dispositions. Psychological Bulletin, 131, 260-301.

Tang, G., Kwan, H. K., Zhang, D., \& Zhu, Z. (2016). Work-family effects of servant leadership: The roles of emotional exhaustion and personal learning. Journal of Business Ethics, 137, 285-297. 
Tekleab, A. G., Sims Jr, H. P., Yun, S., Tesluk, P. E., \& Cox, J. (2008). Are we on the same page? Effects of self-awareness of empowering and transformational leadership. Journal of Leadership \& Organizational Studies, 14, 185-202.

Tims, M., Bakker, A. B., \& Derks, D. (2012). Development and validation of the job crafting scale. Journal of Vocational Behavior, 80, 173-186.

Tims, M., Bakker, A. B., \& Derks, D. (2013). The impact of job crafting on job demands, job resources, and well-being. Journal of Occupational Health Psychology, 18, 230-240.

Tims, M., Bakker, A. B., \& Derks, D. (2014). Daily job crafting and the self-efficacyperformance relationship. Journal of Managerial Psychology, 29, 490-507.

Tims, M., Derks, D., \& Bakker, A. B. (2016). Job crafting and its relationships with person-job fit and meaningfulness: A three-wave study. Journal of Vocational Behavior, 92, 44-53.

Wang, H. J., Demerouti, E., \& Bakker, A. B. (2017). A review of job crafting research: The role of leader behaviors in cultivating successful job crafters. In S. K. Parker \& U. K. Bindl (Eds.), Proactivity at work: Making things happen in organizations (pp.77-104). New York: Routledge.

Wang, Y. H., Hu, C., Hurst, C. S., \& Yang, C. C. (2014). Antecedents and outcomes of career plateaus: The roles of mentoring others and proactive personality. Journal of Vocational Behavior, 85, 319-328.

Webster, J., Beehr, T. A., Love, K. G. (2011). Extending the challenge-hindrance model of occupational stress: The role of appraisal. Journal of Vocational Behavior, 79, 505-516.

Wickramasinghe, V. (2016). The mediating effect of job stress in the relationship between workrelated dimensions and career commitment. Journal of Health Organization and Management, 30, 408-420. 
Wrzesniewski, A., \& Dutton, J. E. (2001). Crafting a job: Revisioning employees as active crafters of their work. Academy of Management Review, 26, 179-201.

Zhang, X., \& Bartol, K. M. (2010). Linking empowering leadership and employee creativity: The influence of psychological empowerment, intrinsic motivation, and creative process engagement. Academy of Management Journal, 53, 107-128. 
Table 1

Descriptive Statistics and Correlations

\begin{tabular}{|c|c|c|c|c|c|c|c|c|c|}
\hline Variables & Mean & $S D$ & $\alpha$ & 1 & 2 & 3 & 4 & 5 & 6 \\
\hline 1. Empowering Leadership (T1) & 3.88 & 0.60 & .89 & & & & & & \\
\hline 2. Job Crafting (T2) & 3.59 & 0.65 & .91 & $.33 * *$ & & & & & \\
\hline 3. Physical Complaints (T3) & 1.65 & 0.52 & .85 & $-.11 *$ & $-.12 *$ & & & & \\
\hline 4. Depression (T3) & 1.72 & 0.71 & .81 & $-.21 * *$ & $-.19 * *$ & $.40 * *$ & & & \\
\hline 5. Career Satisfaction (T3) & 3.70 & 0.93 & .94 & $.32 * *$ & $.32 * *$ & $-.18 * *$ & $-.41 * *$ & & \\
\hline 6. Career Commitment (T3) & 4.96 & 1.28 & .88 & $.25 * *$ & $.42 * *$ & -.09 & $-.26^{* *}$ & $.42 * *$ & \\
\hline 7. Proactive Personality (T2) & 5.29 & 0.92 & .86 & $.25 * *$ & $.55^{* *}$ & $.13 *$ & $-.15^{* *}$ & $.28 * *$ & $.37 * *$ \\
\hline
\end{tabular}


Table 2

Results of Bootstrapping Tests for Estimating Indirect Effects with 95\% Confidence Intervals

\begin{tabular}{|c|c|c|c|c|c|c|c|}
\hline \multirow{2}{*}{ Predictor } & \multirow{2}{*}{ Mediator } & \multirow{2}{*}{ Outcome } & \multirow{2}{*}{$\begin{array}{l}\text { Direct effects } \\
\qquad \beta(p)\end{array}$} & \multicolumn{4}{|c|}{ Indirect effects } \\
\hline & & & & $a b$ & $S E$ & CI 95\% & $k^{2}$ \\
\hline \multirow{4}{*}{$\begin{array}{l}\text { Empowering } \\
\text { Leadership }\end{array}$} & \multirow{4}{*}{$\begin{array}{c}\text { Job } \\
\text { Crafting }\end{array}$} & Physical Complaints & $-.07(.17)$ & -.02 & .02 & $-.06, .00$ & .03 \\
\hline & & Depression & $-.19(.01)$ & -.05 & .02 & $-.10,-.01$ & .04 \\
\hline & & Career Satisfaction & $.37(.00)$ & .12 & .04 & $.05, .20$ & .08 \\
\hline & & Career Commitment & $.28(.01)$ & .26 & .06 & $.16, .39$ & .12 \\
\hline
\end{tabular}

Notes: $N=325 . \beta=c^{\prime}$ (direct effect). $a b=$ unstandardized indirect effect. $S E=$ bootstrap standard error. $a b, S E$, and $C I 95 \%$ were obtained from 10,000 bootstrapped samples. $k^{2}=$ indirect effect/ maximum possible mediation. 
Time 1

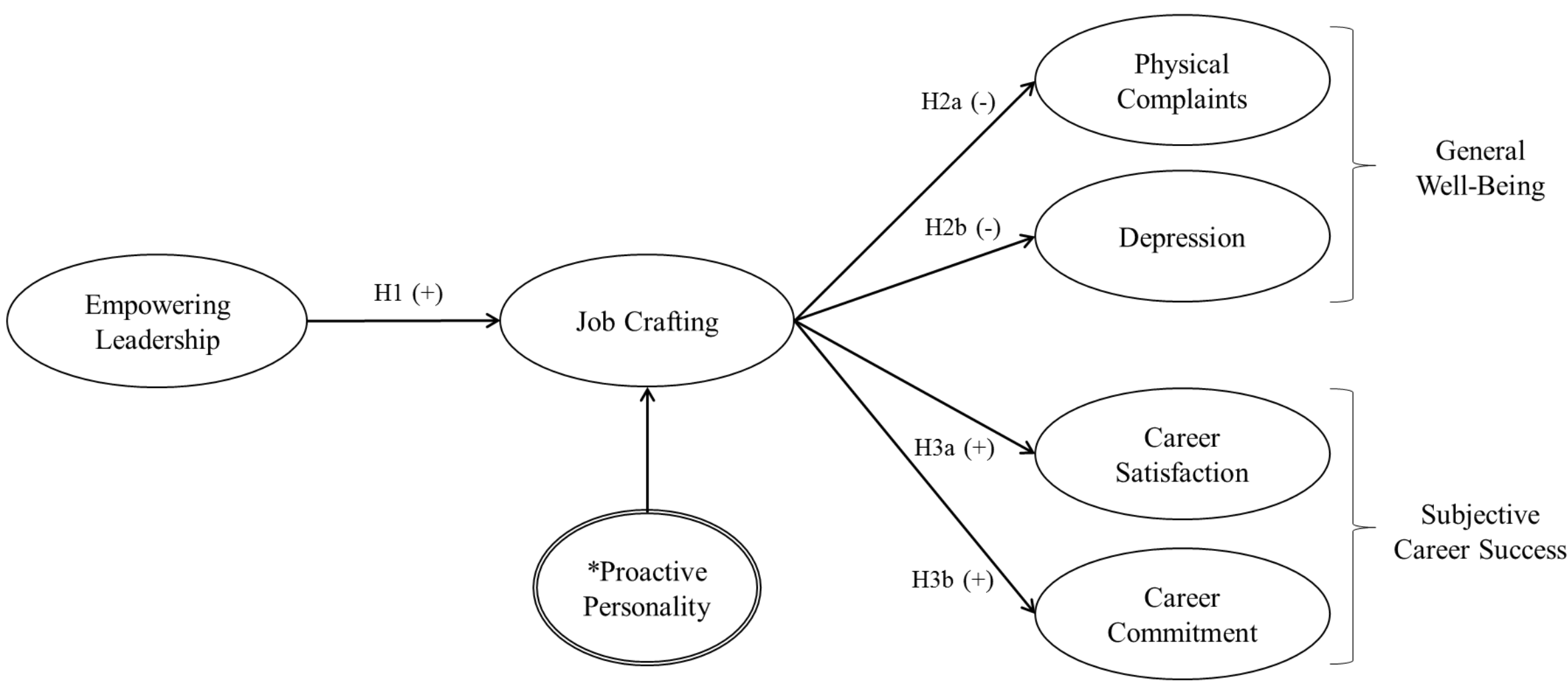

H4 and H5: Mediating Effect

Time 3

Time 2

Physical

Complaints 
Time 1

Time 2

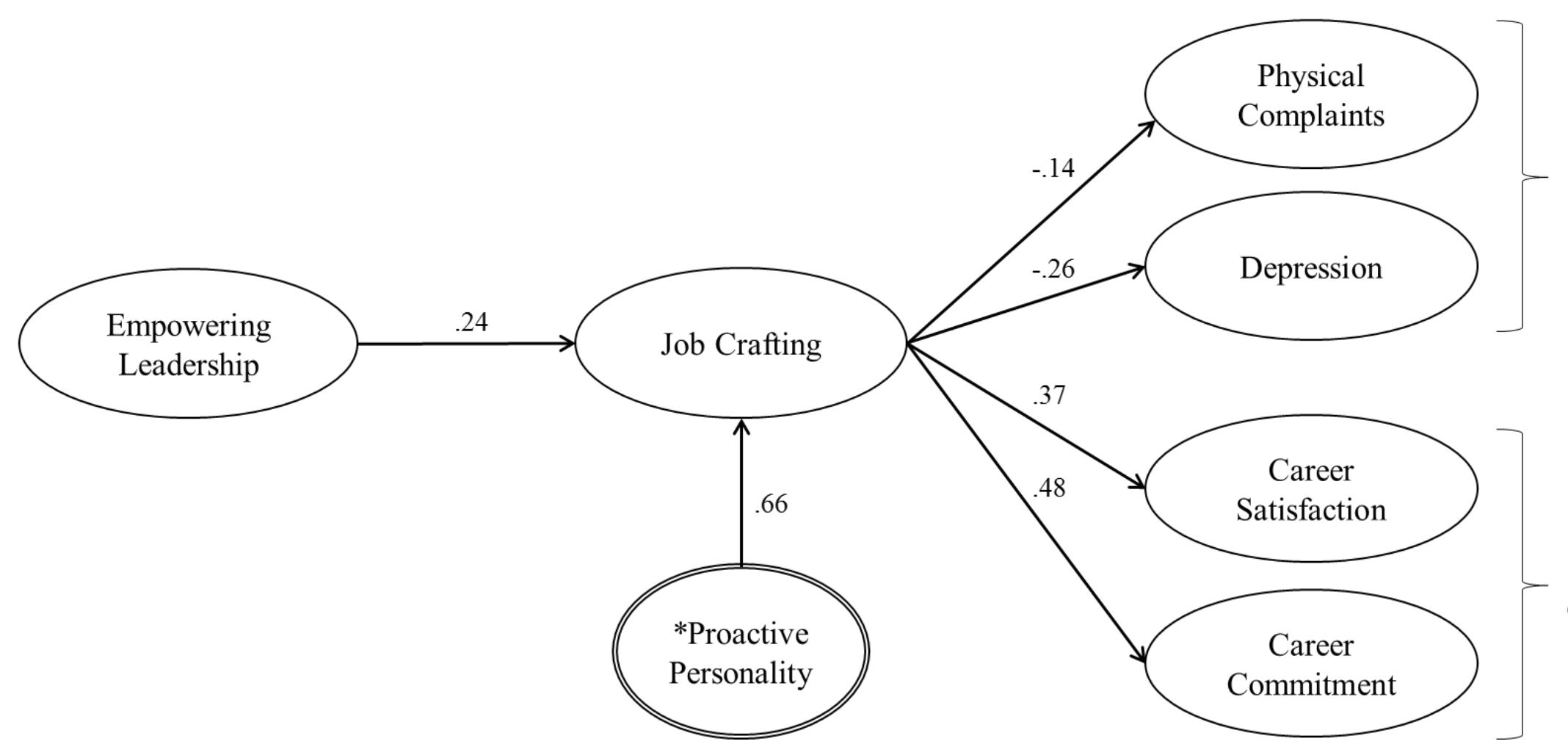

General

Well-Being

Figure 2. Structural Equation Model with Standardized Coefficients

Note: All paths in structural model analysis are significant at $p<.01$ except the path from job crafting to physical complaints $(\beta=-.14, \mathrm{CR}=-2.16, p=.03$. *Proactive personality is a control variable for the prediction of job crafting. 